\title{
Alleviating Poverty through Social Innovation
}

\author{
Agung N.L.I. Fahrudi ${ }^{1}$
}

\begin{abstract}
While various programs have been undertaken by both governmental and non-governmental organizations, poverty is still a big problem globally. Combining the concept of social innovation, social entrepreneurship and frugal innovation, the sort of social innovation aimed to reduce poverty is explored. This type of social innovation is expected to be able to create jobs through entrepreneurship in SMEs and provide affordable basic needs for the poor. Based on the literature, challenges for adopting such innovation are identified and mechanisms for enabling both private and public sectors to work collaboratively in alleviating poverty is proposed.
\end{abstract}

JEL classification: $\mathrm{I} 32, \mathrm{I} 38$

Keywords: social innovation, social entrepreneurship, frugal innovation, poverty, system of innovation

\footnotetext{
${ }^{1}$ Faculty of Administrative Science, Universitas Brawijaya e-mail: agungn_fia@ub.ac.id
} 


\section{Introduction}

Poverty is a global economic, social, political and moral problem around the world (Karnani, 2017). About 10 per cent or more than 700 million of the world population, mostly in developing or emerging economies, still live in extreme poverty and earn less than US\$1.90 per day (United Nations, 2019). In addition, based on OECD data, income inequality has increased in the last decades resulting in a greater gap between the rich and the poor and this can potentially affect economic growth and social cohesion (Cingano, 2014). Income equality in developing countries is typically higher than in developed countries (Dervis and Qureshi, 2016). While various programs have been undertaken by both governmental and non-governmental organizations, poverty is still a big problem globally, and there is a need to find appropriate policies and strategies that enable both private and public sectors to tackle this problem collaboratively (Karnani, 2017).

While Kotler (2015) agrees that capitalism can potentially promote the problems of low wages and poverty, he does not view capitalism as the main driving force in creating poverty. Instead, he argues that the real cause of the problem is the ultimate and solely profit motive of capitalism. As such, many researchers have tried to find a way of enabling businesses to gain profit and deliver positive impacts concurrently. For example, research on social entrepreneurship and social innovation attempts to identify an opportunity in addressing a social problem (Phillips et al., 2015). However, the systematic deployment of social innovation for poverty reduction and sustainable development has not received a disproportionately large share of attention from policy makers, and more research in this area is still needed (Millard et al., 2016). Therefore, this study tries to explore mechanisms for enabling both private and public sectors to work collaboratively within the social entrepreneurial ecosystems in alleviating poverty through social innovation.

In the following sections, the conceptual framework for poverty reduction through social innovation is proposed, and then the conclusion, limitation and future recommendations for further research are given.

\section{Conceptual Framework}

Social innovation is "a novel solution to a social problem that is more effective, efficient, or just than existing solutions and for which the value created accrues primarily to society as a whole rather than private individuals" (Phills et al., 2008, p. 39). Social innovation focuses on addressing a social need while business innovation stresses on meeting market and consumer need (Lettice and Parekh, 2010). Social innovation and social entrepreneurship are closely related in which both of them concern on the identification of opportunity to meet a social need or to address societal challenges (Phillips et al., 2015). As such, social enterprise/business has three key features which involve focusing on social (environmental or cultural) purpose, gaining income from primarily business activities, and aiming for the benefit of something beyond private wealth creation (Burkett, 2010). However, social enterprise and social business are slightly different in which the first tends to skew more towards social objectives in the face of pressure, but in contrast, the latter tends to skew more towards commercial objectives if under pressure (Burkett, 2010).

Next, it will be discussed how social innovation can reduce poverty, challenges for adopting social innovation, and mechanisms for enabling both private and public sectors to collaborate in alleviating poverty.

\section{How can social innovation reduce poverty?}

A large number of initiatives for poverty reduction around the world have been conducted using social innovation, although most of them are not labelled as social innovation (Millard et al., 2016). According to Karnani (2017), poverty reduction initiatives should focus on creating a large scale of jobs suited to the poor. Based on data across 104 developing countries in the Ayyagari et al.'s (2014) study, the small and medium 
enterprise (SMEs, i.e. $<99$ employees) sector's contribution to employment, job creation, and growth was comparable to that of large firms, suggesting the importance of SMEs in creating jobs. Through SMEs, the poor can be producers (not only seen as potential consumers) so that their income can be increased by buying from them (Karnani, 2017). As such, social innovation that supports social change through entrepreneurship in SMEs is required to reduce poverty by creating more jobs and increasing the poor's income. Most importantly, encouraging SMEs to introduce social innovation can also potentially bring greater results for the economy and society, which in turn may lead to increased prosperity. Based on empirical study in the Adriatic Region, SMEs that introduced social innovation had better business performance than those which did not introduce social innovation (Begonja et al., 2016). In addition, SMEs can potentially reduce the economic gap between urban and rural areas since they are more likely to be geographically dispersed than large enterprises (Karnani, 2017). In this way, social innovation and social entrepreneurship in SMEs can altogether accelerate poverty reduction by creating a large scale of employment for the poor, increasing their income, and improving income equality between urban and rural areas.

Karnani (2017) argues that poverty reduction initiatives should not only focus on creating jobs for the poor as mentioned above but also on providing basic public service or need to the poor. Businesses are supposed to be able to make significant profits by selling basic need to the bottom of pyramid (BOP) market or the poor (a large potential market consisting of approximately 4 billion people with per capita income below $\$ 2$ per day) and at the same time bring prosperity to them (Prahalad, 2005). However, the claim of 4 billion consumers in the BOP market around the world is questionable in which people often confuse the emerging middle class in the developing countries for the poor (Karnani, 2017). Lower Class or the poorest of the poor (LC, i.e. an income of $\$ 1.45$ per day with the population around 1 billion) in the BOP market is less likely to be profitable market for most companies than Lower-Middle-Class (LMC, i.e. an income of $\$ 5.68$ per day with the population around 3.7 billion) in the BOP market which is potential to be a profitable market (Subhan \& Khattak, 2017). As such, it is unrealistic to expect significant profit from an LC segment where consumers are still struggling to fulfil their basic needs so that this market is not attractive for businessmen or businesswomen who are expecting for market-rate return. This market is more suitable for social enterprises that want to create great positive impacts, although they may only be able to gain little or belowaverage market return. While the LC alone is a less profitable market, the combination of both LC and LMC in the BOP market are still promising for most enterprises, both for non-profit and profit-oriented enterprises (Subhan \& Khattak, 2017).

Social innovations which directly target the BOP market are still low (Millard et al., 2016). In order to provide quality basic needs at affordable prices for the BOP market, enterprises can also adopt frugal innovation. Weyrauch \& Herstatt (2016) state that the main characteristics of frugal innovation include substantial cost reduction, concentration on core functionalities, and optimised performance level. First, frugal innovations produce solutions at most affordable prices which are significantly lower than existing products or services. Second, these innovations focus on core functionalities which are directly required by users. Lastly, frugal innovations must also meet the minimum performance level required for the intended purpose. For example, MittiCool (a fridge made from clay) was launched at a very low price which was significantly lower $(60 \%$ cheaper) than conventional fridges available in the market. The clay fridge also has very low cost of ownership as it does not need electricity and disposal costs. It also focuses on essential functions for cooling water, fruits, vegetables, and dairy (without freezer compartment and lighting). These functionalities are sufficient for local conditions. The fridge can keep the temperature in the range of 5 to 8 degrees Celsius, enough for cooling fruits, vegetables and dairy in the local climate and conditions (Weyrauch \& Herstatt, 2016). In addition to the above three key features of frugal innovation, more recent literature state that the focus of frugal innovation is shifting to include more attributes such as minimal use of resource and high social impact (Agarwal and Brem, 2017). As such, frugal innovation can also be used to overcome social problems like poverty and inequality and to drive sustainable growth without destroying the environment. In this way, frugal innovation and social innovation share the same mission in addressing social challenges. Based on the above literature, the conceptual framework of social innovation for 
alleviating poverty is proposed in Figure 1. The social innovation for poverty reduction in this study refers to the intersection of social innovation, social entrepreneurship and frugal innovation. This sort of innovation aims to reduce poverty by creating jobs through entrepreneurship in SMEs and provide affordable basic needs for the poor.

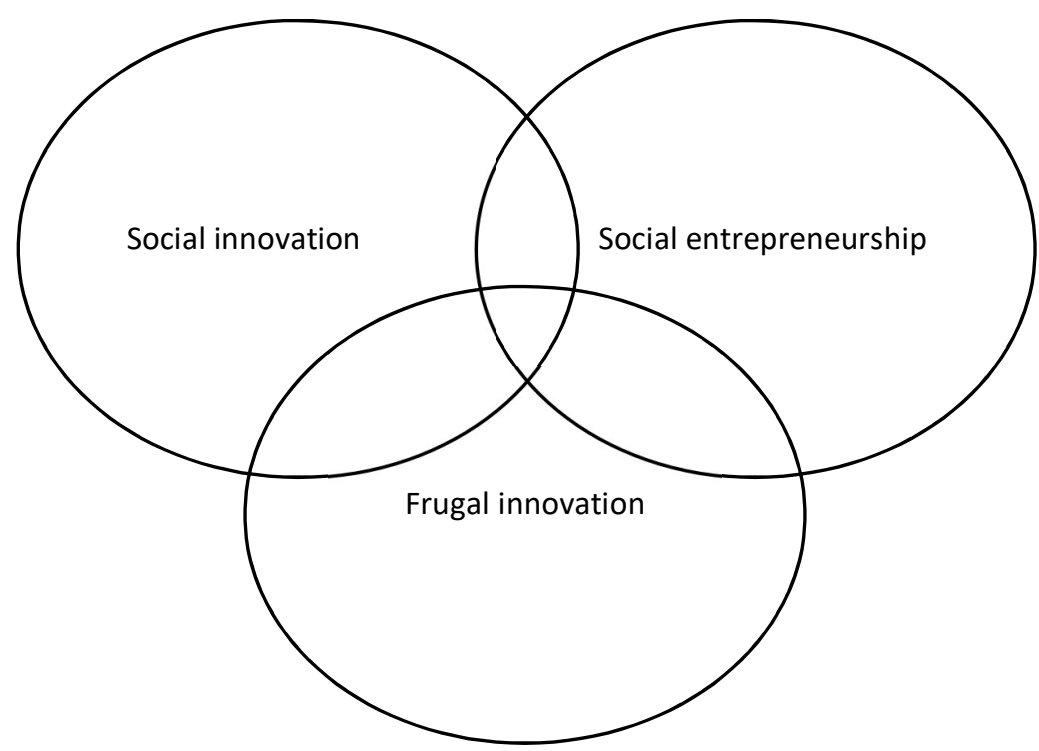

Figure 1. The intersection of social innovation, social entrepreneurship and frugal innovation

\section{Challenges for adopting social innovation}

According to the ASEAN Regional Entrepreneurship Report 2015/2016, the three most pressing constraints for entrepreneurs were financial support, government policies, and capacity for entrepreneurship (Xavier et al., 2015). In terms of financial support, early stage social entrepreneurs in the Indo-Pacific region found it difficult to obtain seed funding and to connect to potential investors (Logue et al., 2017). Additionally, social enterprises may require 'patient' capital with longer or more flexible terms during the growth phases because they often experience precarious cash flow and profitability (Burkett, 2010). In this case, social entrepreneurs may need to target investors who have more concerns on the impacts rather than on the financial return, such as foundations. In addition, in terms of government policies, the government agencies are expected to play a major role in encouraging the financing provision for entrepreneurs, particularly in SMEs, but it does not mean to discourage private investments in this sector (Wonglimpiyarat, 2015). The problems associated with government polices vary across different countries, but mostly the government policies were seen as being unsuccessful in increasing the ease of doing business and simplifying cumbersome bureaucracy (Xavier et al., 2015). Related to the lack of entrepreneurship capacity, Logue et al. (2017) identified the lack of business training opportunities in the Indo-Pacific region and suggested the provision of more accelerators, incubators and coaching agencies. In many countries, capacity building programs for new and existing social entrepreneurs are mostly available in major cities (Logue et al., 2017). As such, it calls more active roles from universities and government in providing entrepreneurial programs that can increase entrepreneurs' likelihood of success (Xavier et al., 2015). 
Fahrudi | Alleviating Poverty through Social Innovation

\section{Mechanisms for enabling both private and public sectors in promoting social innovation}

Social innovation is not developed by lone entrepreneurs in isolation but is formed through interactions of a wide range of organizations and institutions, suggesting the system of innovation importance in the study of social innovation (Phillips et al., 2015). A simple Triple Helix model consisting of university-industrygovernment relations can be used for explaining structural developments in knowledge-based economy, however, this innovation system model can be extended to include more helices when necessary (Leydesdorff, 2012). One type of regional system of innovation is entrepreneurial ecosystems, consisting of key components such as large pools of investment capital, support organizations (i.e. venture incubators and accelerators), labour forces with adequate human capital, and conducive cultures for innovation. In order to support social entrepreneurs, an entrepreneurial ecosystem needs to have diversity in resource providers, adequate support organizations, the ecosystem culture, and opportunities for vicarious entrepreneurial learning (Roundy, 2017).

First, the diversity of investors offering capitals for social entrepreneurs (e.g. impact investments) in the ecosystem can support the creation of social enterprises and increase their chances to succeed (Roundy, 2017). Social entrepreneurs may access capital from microfinance, crowdfunding (an online platform for collecting many small contributions from a large number of people to fund a project or venture), and marketplace for impact investing (investments made into companies, organizations and funds with the aims for both generating positive impacts to society and obtaining a financial return) (Logue et al., 2017). Based on the Global Impact Investor Network Report in 2018, the impact investing industry is growing in which respondents have managed USD 228.1 billion in impact investing assets (Mudaliar et al., 2018). Both developing and developed countries had relatively equal opportunities to impact investing in which $45 \%$ respondents primarily invested in emerging markets and $42 \%$ invested in developed markets. Most impact investors are fund managers and foundations, followed by other significant investors like banks, family offices and pension funds/insurance companies (Mudaliar et al., 2018). As such, in order to increase their likelihood of success, social entrepreneurs within the ecosystem need to understand both available options for financing their social ventures and the way to access these capitals.

Second, social entrepreneurship-focused support organizations (e.g. incubators and accelerators) are needed to provide social entrepreneurs with co-working spaces (facilitating these entrepreneurs to connect to other entrepreneurs), mentorship, and connection to capital providers as well as other support professionals (e.g. accountants, lawyers, and technical advisers) (Roundy, 2017). The support infrastructure also includes universities. Universities can also support social entrepreneurship by providing entrepreneurial programs and creating highly skilled labour forces needed by social ventures. These supports are important for increasing the chances of social entrepreneurs' success because they often lack entrepreneurial capacity (Xavier et al., 2015). In addition, social innovation often needs different sets of skills or capabilities that can hardly be possessed by lone entrepreneurs, requiring cross-sector collaborations (Phillips et al., 2015).

Third, a culture that fosters prosocial actions or more generally altruistic behaviours in an ecosystem is important to cultivate social entrepreneurship (Roundy, 2017). The approach for spiritually sensitive social work movement proposed by Canda (2002) may be useful to create an altruistic culture and can be applied in the social entrepreneurship education required for social innovation. He offers a proactive approach that includes inclusiveness, the use of spiritual traditions, a transformation of social work education, research and theory development, and connectivity in promoting the integration of spirituality and social work. Inclusiveness means social work should involve various religious and non-religious spiritual groups. Approaches to social work and social welfare need to use universal spiritual values rooted in spiritual traditions within each particular country. In addition, relevant spiritual content can be infused into all types of courses in social work education. Research and theory development need to explore values derived from spiritual traditions and sacred scriptures for their relevance to contemporary social work theory and practice. Apart from that, global connectivity among people who are concerned with social work and social welfare 
needs to be developed and maintained so that knowledge exchange can be facilitated among them and they can support each other to work together to solve societal challenges (Canda, 2002).

Lastly, an entrepreneurial ecosystem can facilitate vicarious learning (i.e. learning through observation) in which social entrepreneurs may learn from other traditional entrepreneurs who have sound business knowledge (Roundy, 2017). Social entrepreneurs can connect to other entrepreneurs and learn from each other through a regional network of incubators (Logue et al., 2017). In order to succeed, social entrepreneurs also need to foster cross-sectoral partnership that require cooperation and interactive learning throughout the social innovation process (Phillips et al., 2015).

\section{Conclusion}

Although various programs have been undertaken by both governmental and non-governmental organizations to reduce poverty, the problem of poverty still exists globally. Using the concept of social innovation, social entrepreneurship and frugal innovation, the sort of social innovation aimed to reduce poverty is explored to create jobs through entrepreneurship in SMEs and to provide affordable basic needs for the poor. The three most pressing challenges for entrepreneurship include lack of finance, government policies and lack of capacity. In order to support social entrepreneurs, an entrepreneurial ecosystem will be benefited from having diversity in resource providers, adequate support organizations, the ecosystem culture, and opportunities for vicarious entrepreneurial learning. The relations between university, industry and government are expected to support the social entrepreneurial ecosystems. For example, the government can provide seed funding without overcrowding private funding. More mature social enterprises may access funding from commercial banks or impact investors. In addition, universities may help provide entrepreneurial programs to improve social entrepreneurs' capacities. While the approach in this study can be beneficial for managing collaborations between private and public sectors in promoting social innovation, a contextual approach should be taken into account because different region may have different regulations and cultures. Moreover, more actors or helices in the model may be identified when the situations and conditions call for it.

\section{References}

Agarwal, N. \& Brem, A. 2017. Frugal innovation-past, present and future. IEEE Engineering Management Review, 45, 37-41. https://doi.org/10.1109/EMR.2017.2734320

Ayyagari, M., Demirguc-Kunt, A., \& Maksimovic, V. 2014. Who creates jobs in developing countries? Small Business Economics, 43, 75-99. https://doi.org/10.1007/s11187-014-9549-5

Begonja, M., Cicek, F., Balboni, B., \& Gerbin, A. 2016. Innovation and business performance determinants of SMEs in the Adriatic region that introduced social innovation. Journal of Economic Research, 29, 1136-1149. https://doi.org/10.1080/1331677X.2016.1213651

Burkett, I. 2010. Financing social enterprise: understanding needs and realities. Foresters Community Finance: $\quad$ Brisbane. Available from https://www.aph.gov.au\%2FDocumentStore.ashx\%3Fid\%3D4e8334e0-ef4c-4fc4-bf964e15d1527d3a\&usg=AOvVaw25BTpwsW8ztxvNj32TWBdb [Accessed: 30 November 2019]

Canda, E. 2002. A world-wide view on spirituality and social work: Reflections from the USA experience and suggestions for internationalization. Currents: New Scholarship in the Human Services, 1, 1-6.

Cingano, F. 2014. Trends in income inequality and its impact on economic growth. OECD Social, Employment and Migration Working Papers, No. 163, OECD Publishing. 
Fahrudi | Alleviating Poverty through Social Innovation

Dervis, K. \& Qureshi, Z. 2016. Income distribution within countries: rising inequality. Global Economy and Development Program at Brookings. Available from: https://www.brookings.edu/wpcontent/uploads/2017/12/income-inequality-within-countries august-2016.pdf $\quad$ Accessed: 30 November 2019]

Logue, D., Mcallister, G., \& Schweitzer, J. 2017. Social Entrepreneurship and Impact Investing Report. UTS. Available from: https://www.uts.edu.au/sites/default/files/article/downloads/UTS\%20SEIII\%20Research\%20Repor t 2017.pdf [Accessed: 30 November 2019]

Karnani, A. 2017. Marketing and poverty alleviation: The perspective of the poor. Market, Globalization \& Development Review, 2, 1-18. https://doi.org/10.23860/MGDR-2017-02-01-05

Kotler, P. 2015. Confronting capitalism: Real solutions for a troubled economic system. Amacom.

Leydesdorff, L. 2012. The triple helix, quadruple helix, ..., and an N-tuple of helices: explanatory models for analysing the knowledge-based economy? Journal of Knowledge Economy, 3, 25-35. https://doi.org/10.1007/s13132-011-0049-4

Millard, J., Weerakkody, V., Missi, F., Kapoor, K. \& Fernando, G. 2016. Social innovation for poverty reduction and sustainable development: some governance and policy perspectives. Proceedings of the 9th International Conference on Theory and Practice of Electronic Governance. Montevideo, Uruguay, 153-162. https://doi.org/10.1145/2910019.2910079

Mudaliar, A., Bass, R. \& Dithrich, H. 2018. 2018 Annual Impact Investor Survey. Global Impact Investing Network. Available from: https://thegiin.org/assets/2018 GIIN_Annual_Impact_Investor_Survey webfile.pdf [Accessed: 30 November 2019]

Phills, J. A., Deiglmeier, K., \& Miller, D. T. 2008. Rediscovering social innovation. Stanford Social Innovation Review, 6, 34-43.

Phillips, W., Lee, H., Ghobadian, A., O'regan, N., \& James, P. 2015. Social innovation and social entrepreneurship: A systematic review. Journal of Group \& Management, 40, 428-461. https://doi.org/10.1177/1059601114560063

Prahalad, C. K. 2005. Fortune at the Bottom of the Pyramid: Eradicating Poverty through Profits. Wharton School Publishing.

Roundy, P. 2017. Social entrepreneurship and entrepreneurial ecosystems. International Journal of Social Economics, 44, 1252-1267. https://doi.org/10.1108/IJSE-02-2016-0045

Subhan, F. \& Khattak, A. 2016. What Constitutes the Bottom of the Pyramid (BOP) Market. Institute of Business Administration International Conference on Marketing (IBA-ICM). Kuala Lumpur, Malaysia, 2016.

United Nations. 2019. Goal 1: end poverty in all its forms everywhere. United Nations. Available from: https://www.un.org/sustainabledevelopment/poverty/ [Accessed: 30 November 2019] 
AABFJ | Volume 14, no.1, 2020

Weyrauch, T. \& Herstatt, C. 2017. What is frugal innovation? Three defining criteria. Journal of Frugal Innovation, 2, 1-17. https://doi.org/10.1186/s40669-016-0005-y

Wonglimpiyarat, J. 2015. Challenges of SMEs innovation and entrepreneurial financing. World Journal of Entrepreneurship, Management and Sustainable Development, 11, 295-311. https://doi.org/10.1108/WJEMSD-04-2015-0019

Xavier, S. R., Sidin, S. M., Guelich, U. \& Nawangpalupi, C. 2016. ASEAN Regional Entrepreneurship Report 2015/2016. International Development Research Centre. Available from: https://idl-bncidrc.dspacedirect.org/handle/10625/56932 [Accessed: 30 November 2019] 